\title{
Recent Progress of Spark Plasma Sintering (SPS) Method and Industrial use of Functionally Graded Materials (FGMs)
}

\author{
Masao TOKITA
}

NJSCo.,Ltd.tokita@njs-japan.co.jp

\begin{abstract}
The growth of the advanced functional and structural materials industry, whether for applications of Functionally Graded Materials(FGMs), nano-phase materials, or other new materials must provide the end user with economic value and quality that justifies the commercial cost. The FGMs will always cost more than metallic or ceramic, monolithic or composite alternative materials because of the inherent cost of manufacturing method. Potentials for an industrial use of FGMs are hampered by the lack of an infrastructure for high volume manufacturing facilities at times. In order to overcome those existing issues, the low cost production systems are also desired.

The SPS technique was originally invented in Japan as "Spark Sintering (SS)" in the early 1960s. The SPS has a high potential to be a major FGMs manufacturing method in the various industries provided the developments necessary, therefore, is now challenging both high-value added small scale and mass-production area to apply newly developed 5th generation SPS systems and processes.
\end{abstract}

Keywords: Spark Plasma Sintering, SPS, wear-resistant materials, WC/Ni FGMs, Industrialization

\section{Introduction}

Spark Plasma Sintering (SPS) method is widely recognized as useful sintering technique to develop various kinds of attractive metals, ceramics and composite materials due to its excellent features of a rapid heating, an electro-magnetic field effect, a well-controlled microstructure and a fabrication of nano-phase materials, thermoelectric materials, Functionally Graded Materials (FGMs)[1-3]. Since two and half decades ago, Spark Plasma Sintering (SPS) method is of great interest to the powder and powder metallurgy industry and material researchers of academia for both product manufacturing and advanced material research and development. The SPS features to provide a rapid sintering as one of remarkable advantage of SPS technique with microstructure controlled sintering. Structurally tailoring effect in SPS processing was verified in the consolidation of nano- $\mathrm{Al}_{2} \mathrm{O} 3, \mathrm{CeO} 2, \mathrm{WC}, \mathrm{SiC}$ and others. Utilizing the SPS technique in FGMs fabrication to comply with industrial demands quality level, cost and commercial production scale, it is needed to develop optimum sintering conditions obtaining dense and homogeneous large-sized FGMs with a finer grain structure and better mechanical properties. It is well known that SPS sintering temperature distribution behaviour is so much different between small specimen of 20-50mm in diameter and large size of more than $100 \mathrm{~mm}$ [4]. To ensure the high reliability, reproducibility and productivity by SPS, it is also needed to develop a suitable advanced SPS machine systems which is so-called the 5th generation-type SPS systems for production use. Figure 1 shows Progress of SPS Technology and Figure 2 shows an example of newly developed advanced large SPS apparatus.Scaling - up technique and Multi-cavity laminated SPS sintering process will be studied.

This paper firstly introduces a brief historical review on progress of SPS technology is given and the applicable field and systems are exemplified. Then, the development of WC/Ni FGMs component example in practical use of Extruding Machine Screw application will be introduced.

Presenting and corresponding author: name, address

Masao TOKITA: Office-Shin Yokohama build.3F,2-14-8 Shin-Yokohama, Kouhoku-ku, Yokohama-shi, Kanagawa, 222-0033, JAPAN 


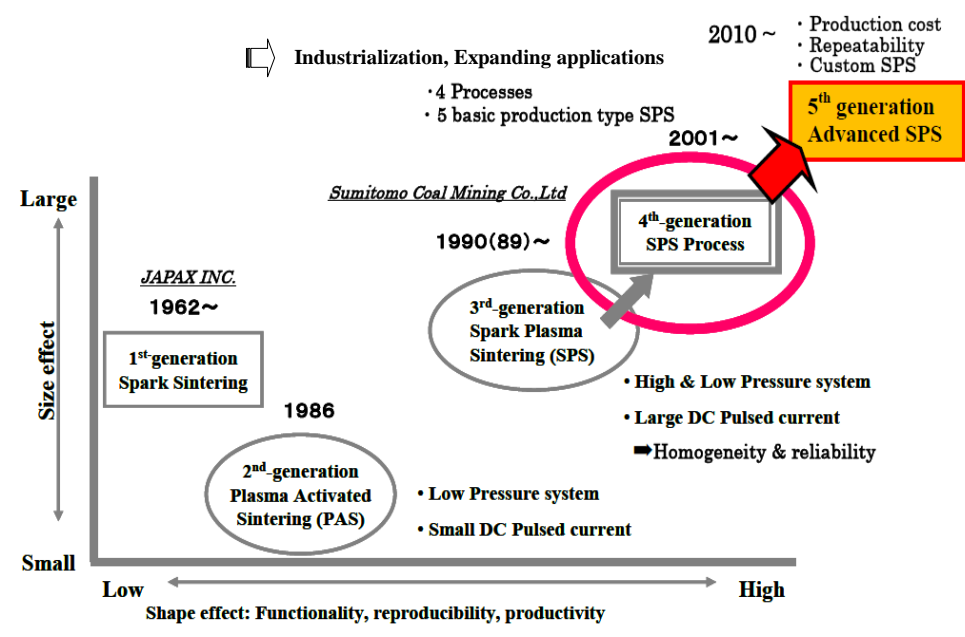

Figure 1: Progress of SPS Technology

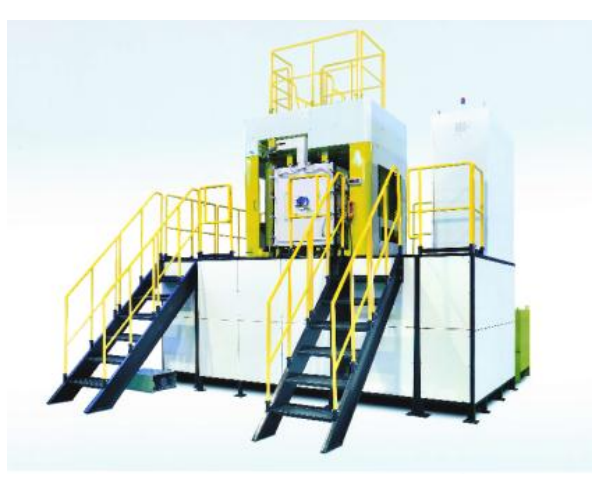

Figure 2: The 5th generation Large SPS Apparatus (Model:JPX-300GIII 3MN/30,000A DC pulse generator)

\section{Basic SPS Processing precedure and FGMs}

In order to obtain a dense or a porous good sintered compact, it is proposed Basic SPS Processing procedures for sintering experimental program as shown in Figure 3. This proposed cyclic testing method can solve the problems to obtain the healthy SPSed compact with homogeneity. The first step of the procedure is to select the suitable starting powder material and to provide particular size with configuration of SPS sintering punch and die assembly. Then, it is executed small sized sample making test (normally $\Phi 20 \mathrm{~mm}$ ) with different sintering conditions of pressure, temperature and heating rate to understand the SPS sintering tendency, sinterability and the powder characteristics. They are observed and analyzed the microstructure, composition, density, hardness, fracture toughness strength etc., to understand differences in heat distribution and densification behavior. The grain growth and grain boundary status are also studied. Considering the preliminary test result of the first stage including re-trial tests, it is further prepared the final SPS sintered compact with desired density and mechanical and/or electrical properties by giving priority to either sintering pressure and temperature, or changing all sintering conditions except "die and punches structure and powder material", and optimizing refinement of sintering conditions. If it was not reached at the appropriate goal in the second stage, it will be changed "die structure and material" to fabricate the SPS sintered compact with desired density and properties in the3rd/4th stages.

According to our recent experiment as shown in Figure 4, it is suggested that Raman scattering method for the purpose of examining the crystallographic state of zirconia and the internal stress in the respective 7 layers of the SPS-synthesized $\mathrm{ZrO} 2(3 \mathrm{Y}) /$ stainless steel(SUS410L) FGM was effective[5].
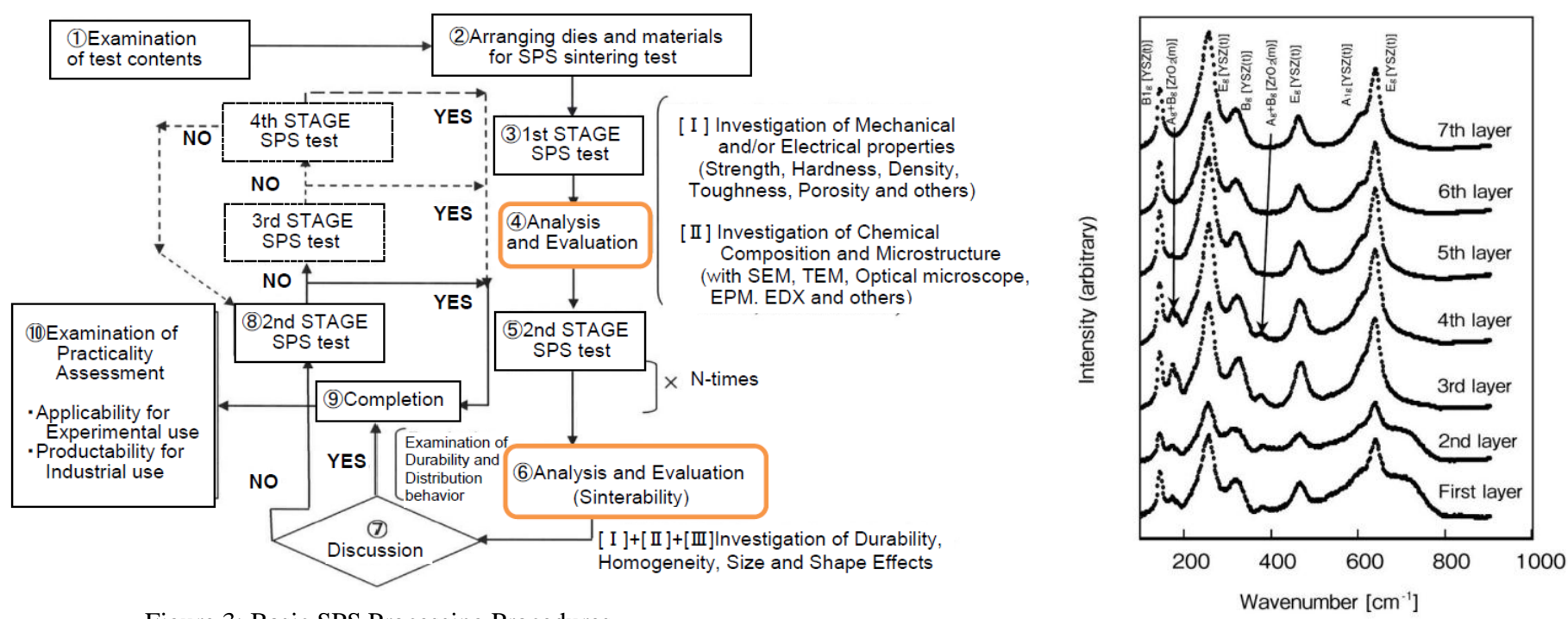

Figure 3: Basic SPS Processing Procedures

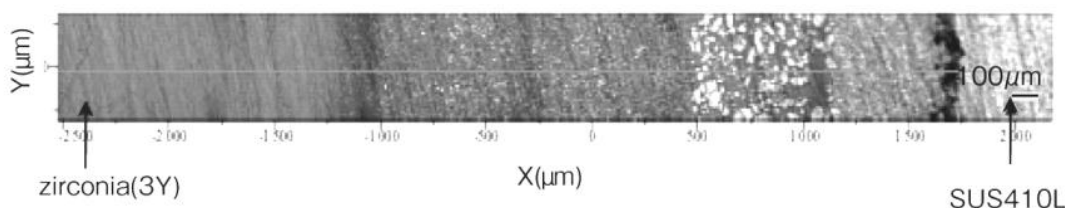

Figure 4: Optical photograph of cross section of $\mathrm{ZrO}_{2}(3 \mathrm{Y}) / \mathrm{SUS} 410 \mathrm{~L}$ FGM and Raman scattering spectra obtained from zirconia in each layer of $\mathrm{ZrO}_{2}(3 \mathrm{Y}) / \mathrm{SUS} 410 \mathrm{~L}$. 


\section{Example of SPSed WC/Co/Ni FGMs for Industrial Applications}

Near-net shape forming and scaling-up process on square-shaped FGMs were studied. As a typical high wear-resistant material, $\mathrm{WC} / \mathrm{Co}$ or $\mathrm{WC} / \mathrm{Ni}$ system cemented carbide are now widely used in various press-stamping dies and cutting tools for industrial applications. The FGMs by SPS process presents many excellent including simple control of sintering energy, ease of handling and elimination of sintering skills, as well as high sintering speed and productivity, safety, space saving, energy saving and low equipment cost. However, it is suggested that the simultaneous development concept that of SPS software development technology involving the powder preparation and SPS machine hardware technology should be studied at a time to realize cost effective manufacturing method for the practical industrial applications. Figure 5 shows a square-shaped large size WC/Co FGM with dimensions of $100 \mathrm{~mm}$ (width) $\times 100 \mathrm{~mm}$ (length) $\times 40 \mathrm{~mm}$ (thickness) with 4 layered composition fabricated by SPS. The cobalt concentration and the starting powder particle sizes were graded to $\mathrm{WC} 0.5 \mu \mathrm{m} / \mathrm{Co} 6 \mathrm{wt} \%$, $\mathrm{WC} 3.5 \mu \mathrm{m} / \mathrm{Co} 14 \mathrm{wt} \%$, WC $5 \mu \mathrm{m} / \mathrm{Co} 20 \mathrm{wt} \%$ and $\mathrm{WC} 9 \mu \mathrm{m} / \mathrm{Co} 20 \mathrm{wt} \%$ and thickness of the each layer were $5 \mathrm{~mm}, 7 \mathrm{~mm}, 8 \mathrm{~mm}$ and $20 \mathrm{~mm}$ respectively. The sintered bulk FGM was machined by a numerically controlled wire-cut electrical discharge machine (EDM) to cut-off from the large bulk material to the small pieces of FGM block. As shown in Figure 6, the small piece of WC/Co FGMs were usually ground to form the specified profiles, accuracies and tolerances as press stamping dies and punches by a precision type of grinding machine. Concerning its mechanical properties, the SPSed fine WC/Co FGM hard alloy had higher hardness of Hv20GPa on top coat layer and higher strength and fracture toughness with Hv9GPa in bottom side than mono-WC/Co hard alloy materials. When assembled as press stamping progressive die and punch, it achieved approximately 3.5 to 10 times longer life time compared with conventional commercial cemented carbide products.

Generally, conventional monolithic tungsten carbide is not available to weld by TIG welding. Therefore, in addition to a hardness gradient material, a functional material of weldable WC/Ni FGM with WC $90 \% / \mathrm{Ni} 10 \mathrm{wt} \%$, WC $80 \% / 20 \mathrm{wt} \%$ and WC70\%/30wt\%, 3 layers was also developed. As shown in Figure 7, the application example for Screw of Extruding Machine employing weldable WC/Ni FGM, the life time was over 3 times longer that was more than 3,000 hours than conventional screw of 800 hours [6]. To improve the SPS productivity, multi-assembly temperature gradient sintering method was successfully developed. Figure 8 shows the one set of die \& punches assembly(mold) made of graphite at left, 4-multi SPS sintering stage(center) and 4 plates of a fan square-shape SPS sintered compacts at right.

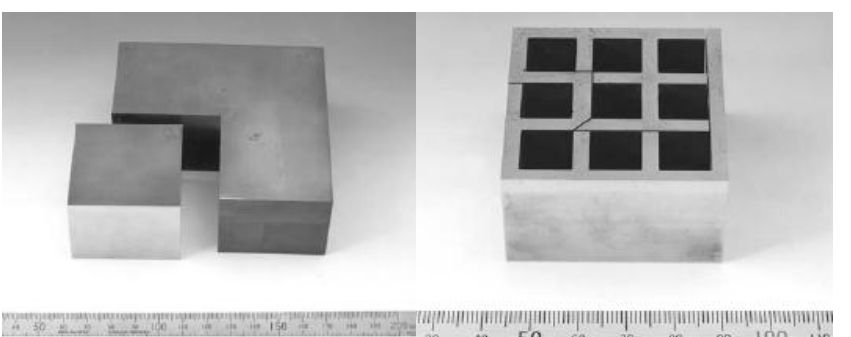

Figure 5: Large-size WC//Co FGM and cut-off sample by wire-cut electrical discharge machine

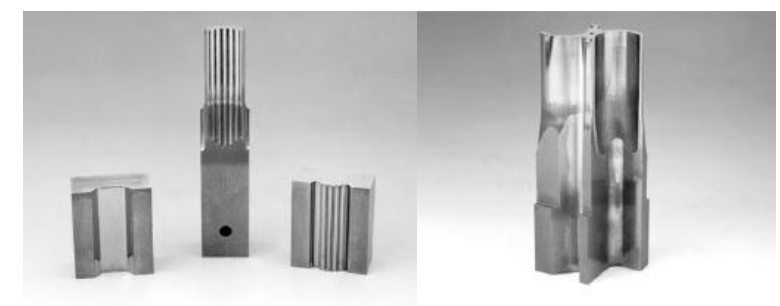

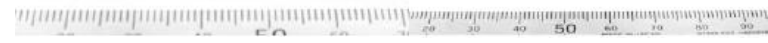

Figure 6: Examples of press stamping die and punch made of WC/Co FGMs for electronic component
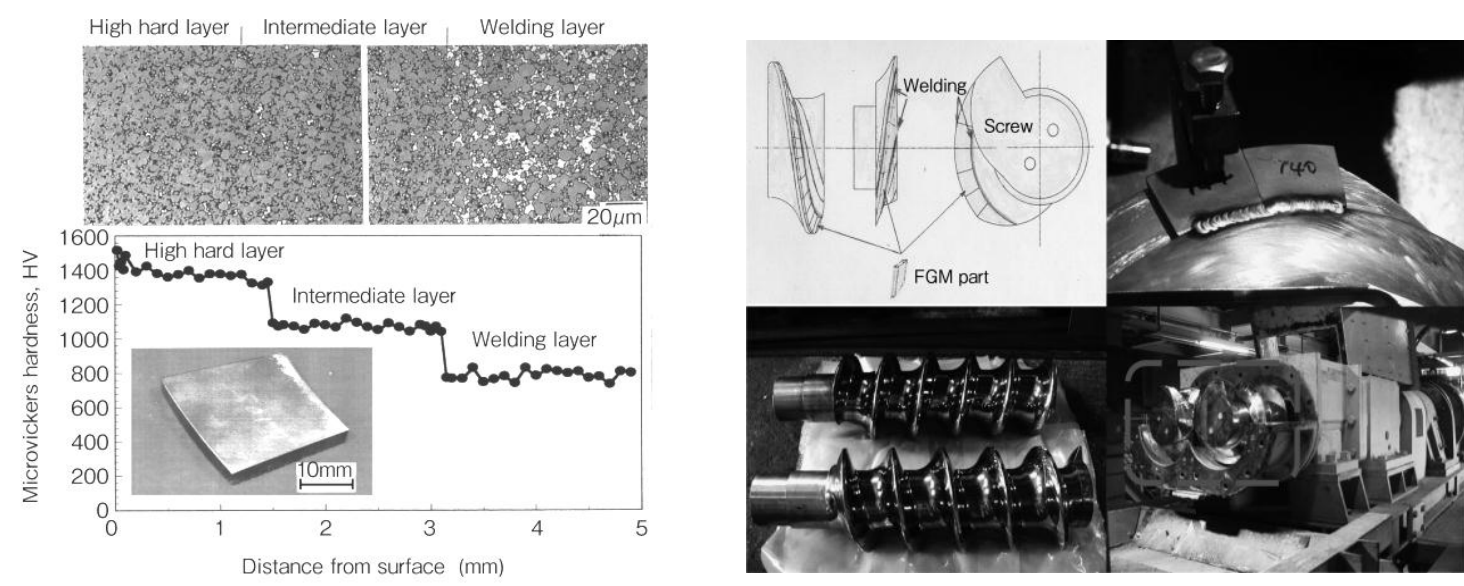

Figure 7: Optical microphotograph and Vickers hardness distribution behavior of weldable WC/Ni FGM tile and the FGM screw product for the extruding machine 

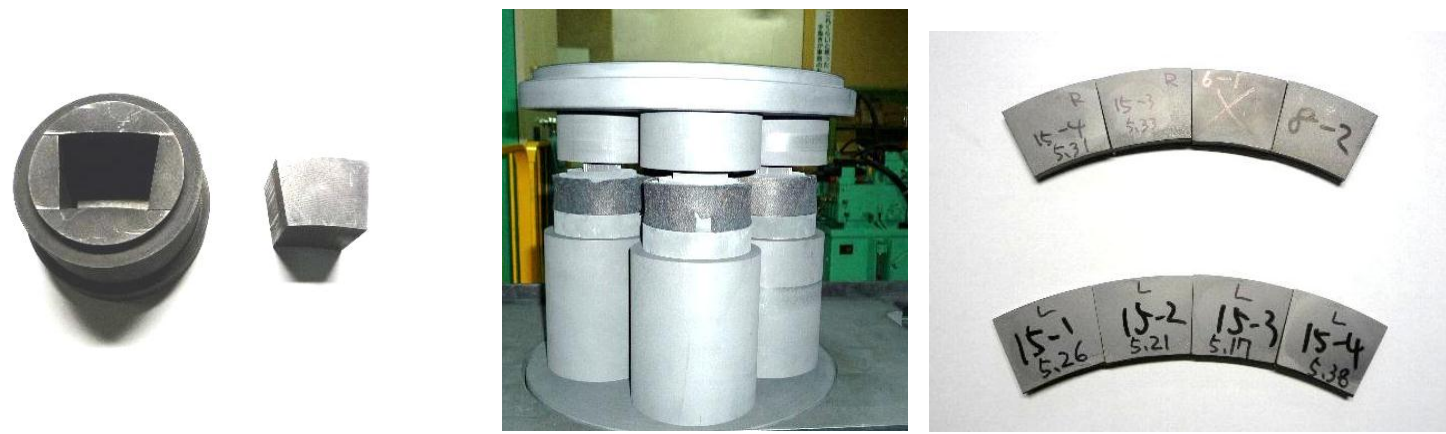

Figure 8: 4-Multi assembly SPS method

(Left:Die \& Punch, Center:SPS stage, SPS sintered compacts 4 plates at a time)

\section{Automated SPS Production Systems}

Figure 9 shows a tunnel-type the world largest SPS Pproduction System with 3-chambers. As a future prospect of SPS technology, it is expected that a fully automated SPS systems will be used in industries and increasing gradually. The SPS has the potential to be a major product manufacturing tool in the automotive, electronics, mold \& tooling and aero-space industries provided the development necessary to overcome some of the current inhibitors, such as lack of infrastructure for mass production, environmental concerns, inhomogeneity, cost issues etc., can be circumvented.Through the use of SPS production systems in Japan, a cost-effective production has already been realized in several practical applications since productivities by this method ensuring comparable or exceeding results compared with conventional sintering processes of hot pressing, hot isostatic pressing(HIP) and pressureless sinterig. As an example shown in this paper, the FGMs by SPS process offers products with new functionalities and good mechanical properties equivalent or exceeding to that of commercially available current materials in areas such as hardness, toughness and life-time. A review of patents on SPS technology leads us into next considerable progress[7]. It is critical to explore further new manufacturing systems from the viewpoint of dynamically integrated reactive processing, which develops both of software and hardware simultaneously by investigating sintering purpose, product cost, characteristics cost of raw powder materials and manufacturing processes. These advanced total processes should soon make it possible to eliminate the present relatively laborious and time consuming methods for processing and optimizing sintered structures and functions.
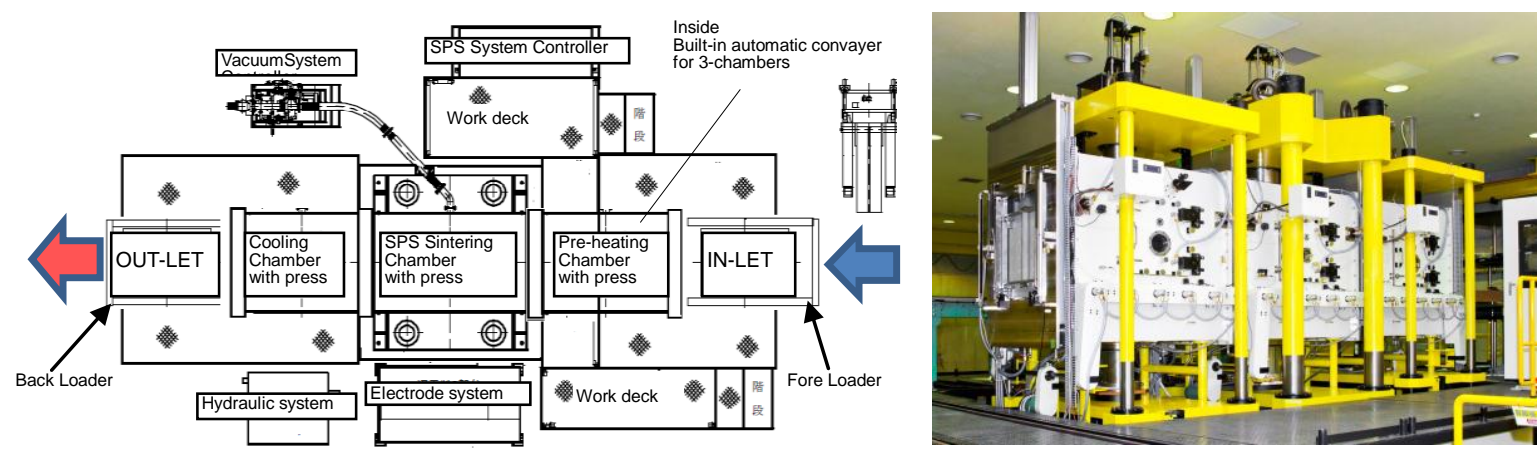

Figure 9: Continuous SPS system concept and the world's largest semi-tunnel type automatic SPS production system (3-vacuum chamber system, 6MN press machine with 40,000A DC pulse generator with a special conveyer)

\section{Summary}

SPS features an electrical energy concentration at areas where current flows easily. In terms of the high energy density and dynamical processing, the study on these characteristics will lead us to the successful advancement and expanded SPS applications for reasonable commercial production as future prospects of SPS technologies,

\section{References}

1. K. Inoue, "Electric Discharge Sintering”, U.S.Patent No 3,241,956(1966) ( Ser.No.247,387 filed 1962).

2. M. Tokita, Ceramic Transaction Vol.194, Am. Ceram. Soc., Wiley-Interscience, (2006)51-60

3. Z.A. Munir, U.Anselmi-Tamburini, M. Ohyanagi, J. Material Science, 41 (2006)763-777

4. M. Tokita,. Advances in Science and Technology Vol.63(2010)322-331

5. M, Tokita, M. Kawahara, K. Mizuuchi and Y. Makino, J.Jpn.Soc. Powder and Powder Metallurgy, 56[6] (2009)383-388

6. M. Tokita, Materials Science Forum, Vols.492-493 (2005)711-718

7. S. Grasso, Y. Sakka and G. Maizza, , Science and Technology of Advanced Materials, Vol.10 (2009)1-24 